\title{
THE PERCEIVED EFFECTS OF MARIJUANA ON SPINAL CORD INJURED MALES
}

\author{
By Michael Dunn, Ph.D., and Ross Davis, M.D. \\ Spinal Cord Injury Service, Veterans Administration Hospital, \\ Miami, Florida
}

A RECENT, informal, confidential survey was taken on the Spinal Cord Injury ward of the Miami V.A. Hospital concerning the effects of marijuana on pain and spasticity in spinal cord injured males. Ten patients who admitted that they had used marijuana after they had been injured were asked how the drug affected burning, phantom pain, muscle spasms, bladder spasms, urinary retention, headache pain and pleasant sensations. The following table indicates the number of patients in each category with the column labelled 'Distract' indicating that the drug did not decrease the pain but helped the patient pay less attention to it and the column labelled 'Not applicable' indicating that the patient did not experience the sensation in the non-drug state.

\begin{tabular}{|l|c|c|c|c|c|}
\hline & Increase & Decrease & $\begin{array}{c}\text { No } \\
\text { effect }\end{array}$ & Distract & $\begin{array}{c}\text { Not } \\
\text { applicable }\end{array}$ \\
\hline Phantom pain & I & 4 & 2 & 2 & I \\
Spasticity & - & 5 & 3 & - & 2 \\
Bladder spasms & I & I & 7 & - & I \\
Urinary retention & 2 & - & 8 & - & I \\
Peadache pain & - & 5 & 4 & - & - \\
\hline
\end{tabular}

The perceived decrease in pain and spasticity shown by this survey, even though replies may be biased, indicates that better controlled studies would be worth while. 